\title{
Analysis of used oil on the basis of wear volume using Taguchi method
}

\author{
Abhay D Kulkarni ${ }^{1}$, Dr. Geeta Lathkar ${ }^{2}$ \\ ${ }^{1}$ (Department of mechanical, M.G.M College/ SRTU, Nanded, India) \\ ${ }^{2}$ (Director, M.G.M College of engineering/SRTU, Nanded, India)
}

\begin{abstract}
In heavy forging machines lubricants come under very high contact forces which degrade the lubricant oil .Number of factors are responsible for this degradation they are like, working temperature, load, speed and environment These are common in hot forging machines. In this present work, new and used lubricant samples are evaluated and compared for the wear volume using crossed cylinder test method. Here constant test conditions were a) sliding speed $1.3 \mathrm{M} / \mathrm{sec}$ and b) temperature $28^{\circ} \mathrm{c}$. We tested new and used oil samples are tested for different parameters like, used hours of oil, sliding distance and) load. Cross cylinder test method was found effective and simple. Here we used the traditional Taguchi's method which optimized test parameters .Results were analysed by the ANOVA and F-tests. Confirmatory tests showed that the results were within the confidence interval.
\end{abstract}

Keywords: - Cross cylinder test, lubricated wears, sliding contact, Taguchi method, oil analysis

\section{INTRODUCTION}

The operational life of most of the industrial machinery is directly related to the condition of the lubricants. Lot of research was done on lubricant oil testing with cross cylinder test method but very considerable work has not been done on used oil .The contribution towards the first contact model was proposed by Heinrich Hertz (1881-1882) investigated the conductance between two crossed cylinders with the same reference Bowden and Tabor (1942) explained the theory based on the basis of a) The friction force is dependent on real area of contact between two bodies b) The friction force is dependent on shearing strength of adhesive bond formed between two bodies at tip of asperities [1]. Archard (1953) examined the friction and wear process and decided that there are a number of key considerations that must be included in a wear model. $\mathrm{He}$ endeavored to incorporate these disparate variables in to one predictive equation and proposed first wear laws. These considerations were the wear mechanism (adhesion), area of contact, contact pressure, sliding distance and the material properties [2,3]. Based on his various experiments Archard derived the following conclusions1) the material volume removed by wear is proportional to the sliding distance; 2) the material volume removed by wear is proportional to the normal applied load; 3) the materials display a wear amount inversely proportional to their hardness. In this present work cross cylinder test is used as testing method .Recent studies have showed that the crossed-cylinders wear test is a useful and reliable method and could be applied as a cheap laboratory technique to pre-screen new lubricant formulations and materials selections [4]. A.W.Ruff and N.K.Myshkin have used this standard crossed-cylinder wear test geometry to compare lubricating liquids like pure paraffin oil with and without the addition of oleic acid and then wear and friction coefficient data were obtained. [5]. Begelinger et.al, evaluated the running-in characteristics of lubricants and proposed special running-in fluids under practical conditions of surface roughness by testing with crossed cylinders [6]. B. Zhu and G.L. Kelly carried out experimental investigations of wear coating under unlubricated (dry) and lubricated conditions. [4]. S. M. Mahdavian, et.al studied the variation in the coefficient of friction with sliding distance for different sliding conditions for both similar and dissimilar metals in a Crossed-cylinder geometry[7]. S. M. Mahdavian and Y. W. Mai, studied and shown that there are some distinct differences in the absolute magnitudes of the friction coefficients owing to variations in the ploughing intensity, metal transfer and embedding as affected by the two test geometries [8].In order to obtain minimum wear optimization of the process is necessary. Taguchi method is a systematic application of analysis of experiments for the purpose of designing and improving working conditions. Here it is used especially for evaluating several process factors at a time with the smallest number of experimental runs based on a table, known as the orthogonal array [9]. The objective is to study was to analyse the parameters considered using the Taguchi method to determine, the optimum combination of the chosen parameters to minimize the wear of the material.

\section{EXPERIMENTAL WORK}

All these tests are conducted with the lubricated crossed cylinder testing machine. Technical Data: Dimensions (L x W x H): 540 × $390 \times 275 \mathrm{~mm}$, consisting of Main unit with engine, lever system and base plate. In the 
crossed-cylinder wear test, two cylindrical specimen are perpendicular to each other; one with sliding speed is $1.2 \mathrm{~m} / \mathrm{s}$. The stationary specimen of diameter is $18 \mathrm{~mm}$ and rotating cylinder of $25 \mathrm{~mm}$ diameter. The normal load is applied by means of a mechanical lever system. Before starting the experiments, both samples (fixed cylinder and rotating cylinder) were cleaned with Petroleum Benzene. The lubricant to test is poured over the test ring. The test cylinder is then pressed on the test ring by a lever system. Due to the cross arrangement of the axles, an elliptical wear mark will be formed as shown in figure 1. Wear test is performed with the parameters and wear scar is then measured using measuring magnifier. Both test ring and test cylinder can also consist of different materials; this allows the testing of various material matching. The entire test is carried out at constant temperature $28^{\circ} \mathrm{C}$. Here for calculating wear volume of the stationary specimen, the volume of the wear scar can be calculated assuming an imposed wear shape using the approximate expression.

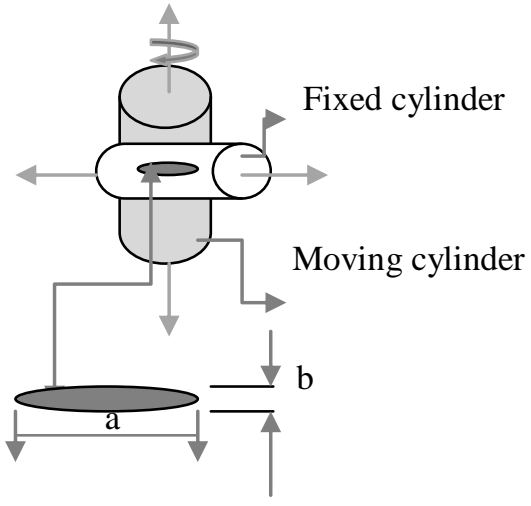

Fig.1 Cross cylinder arrangement with fixed and moving cylinder and wear mark

$\mathrm{V}=\Pi / 2 \mathrm{~h}^{2}\left(\mathrm{r}_{1 *} \mathrm{r}_{2}\right)^{1 / 2}$, (1) Where $\mathrm{r}_{1}$ is the radius of the stationary specimen, $r_{2}$ is the radius of the rotating specimen and $\mathrm{h}$ is the depth of the scar. Each scar is measured by taking the larger a and the smaller $\mathrm{b}$, dimensions of the wear surface. The value of scar depth can be calculated using following equations. $\mathrm{h}_{2}=\mathrm{r}_{2^{-}}\left(\mathrm{r}_{2}^{2}-(\mathrm{b} / 2)^{2}\right)^{1 / 2},(2) . \quad \mathrm{h}_{1}=\mathrm{r}_{1}-\left(\mathrm{r}_{1}^{2}-(\mathrm{a} / 2)^{2}\right)^{1 / 2}$, (3). From both these equations 1 and 2 the total wear scar depth $h$ calculated as average of $h_{1}$ and $h_{2}[10,11,12]$.

\section{TAGUCHI APPROACH}

Taguchi method is a powerful tool for the design of high-quality systems. It provides a simple, efficient and systematic approach to optimize the designs for performance, quality, and cost [13]. Set of experiments were done using Taguchi`s experimental design to evaluate the four factors at three points each (Table 1). The four factors are A) Sliding time B)Lubricant types C)Load applied c)Used hours of lubricants. To observe the fine changes in profile geometry these wear tests were carried out by changing the test parameters. The lists of test parameters which may have an impact on wear volume were identified. Some of the parameters were kept constant while studying characteristics during the experiment. The following major parameters were varied each at three different levels. Taguchi method involves the parametric combination of a large number of experimental situations, described as orthogonal arrays, to reduce errors and enhance the efficiency and reproducibility of the experiments. Orthogonal arrays are a set of tables of numbers, which can be used to efficiently accomplish optimal experimental designs by considering a number of experimental situations [14].

Table 1 Wear volume parameters and their Levels

\begin{tabular}{ccccc}
\hline & & & & \\
& Factor & Level-1 & Level-2 & Level-3 \\
\hline A & Sliding time(second) & 10 & & \\
B & lubricants & Sample 1 & Sample 2 & Sample3 \\
C & Load(N) & 400 & 450 & 500 \\
D & Lubricant used & new & 1000 & 4000 \\
& hours(hours) & & & \\
\hline
\end{tabular}

An experimental design methodology adopting the Taguchi approach was employed in this study, with the orthogonal array design used to screen the effects of four parameters, including the sliding time, oil samples, load applied and lubricant used hours The diversity of factors was studied by crossing the orthogonal array of the control .In this study, Minitab 14, which is software for the Automatic Design and Analysis of Taguchi 
Experiments, was used to analyze the results and optimize the experiment conditions for setting the control variables.

Table 2: Orthogonal array used to design experiments with four parameters at three-levels,

\begin{tabular}{ccccc}
\hline Sr No. & \multicolumn{4}{c}{ Parameters and their levels } \\
\cline { 2 - 5 } 1 & $\begin{array}{c}\text { (A)Sliding } \\
\text { time(Second) }\end{array}$ & (B)lubricants & $(\mathrm{C})$ Load(N) & $\begin{array}{c}\text { (D)Lube used } \\
\text { hours(hours) }\end{array}$ \\
\cline { 2 - 5 } 2 & 1 & 1 & 1 & 1 \\
3 & 1 & 2 & 2 & 2 \\
4 & 1 & 3 & 3 & 3 \\
5 & 2 & 1 & 2 & 3 \\
6 & 2 & 2 & 3 & 1 \\
7 & 2 & 3 & 1 & 2 \\
8 & 3 & 1 & 3 & 3 \\
9 & 3 & 2 & 1 & 1 \\
\hline
\end{tabular}

\section{RESULT AND DISCUSSION}

The results, in terms of wear volume were obtained after conducting the crossed cylinder test for all types of lubricants. Each test specimen represented one experiment in the orthogonal array (Table 2). The experimental results for wear volume under the application of specified parameters are summarized in Table 3. In the latter, the results were analyzed by employing main effects, ANOVA, and the signal-to-noise ratio $(\mathrm{S} / \mathrm{N})$ analyses. Finally, a confirmation test was carried out to compare the experimental results with the estimated results. The results for response values have been tabulated in Table 4. To obtain optimum process parameters setting, Taguchi proposed a statistical measure of performance called signal to noise ratio. There are three types of the performance characteristics in the analysis of the signal-to-noise ratio, i.e. the lower-the-better, the higher-thebetter, and the nominal- the-better [9].

Table 3.Taguchi orthogonal Array L9, their responses, mean and s/n values for wear volume

\begin{tabular}{cccccl}
\hline Sr.No & Level-1 & Level-2 & Level-3 & Mean $\left(\mathrm{mm}^{3)}\right.$ & s/n values \\
\hline 1 & 0.13 & 0.138 & 0.269 & 0.179 & 14.4247 \\
2 & 0.502 & 0.523 & 0.565 & 0.53 & 5.50388 \\
3 & 1.185 & 1.31 & 1.393 & 1.297 & -2.277 \\
4 & 1.393 & 1.483 & 1.583 & 1.4863 & -3.45415 \\
5 & 1.234 & 1.273 & 1.313 & 1.274 & -2.10163 \\
6 & 1.142 & 1.185 & 1.234 & 1.187 & -1.49337 \\
7 & 1.783 & 1.845 & 1.956 & 1.8613 & -5.4029 \\
8 & 1.313 & 1.39 & 1.44 & 1.381 & -2.81008 \\
9 & 1.745 & 1.837 & 1.845 & 1.809 & -5.1515 \\
\hline
\end{tabular}

For minimum wear Smaller the better system is applied (for making the system response as small as possible) $\mathrm{S} / \mathrm{N}=-10 * \log 1 / \mathrm{n} * \sum_{i=0}^{n} \mathrm{y}_{\mathrm{i}}{ }^{2}$, (4) where $(\mathrm{S} / \mathrm{N}){ }^{`} \mathrm{~s}$-signal to noise ratios, $\mathrm{y}_{\mathrm{i}}{ }^{2}=$ Variance of $\mathrm{y}, \mathrm{n}=$ Number of observation [9] .This table also contain delta which is the difference between the highest $\mathrm{S} / \mathrm{N}$ ratio and the 
lowest $\mathrm{S} / \mathrm{N}$ ratio. Ranks are assigned on the basis of the delta value; rank 1 is assigned to highest delta value, rank 2 is assigned to next highest value and so on.

Table 4.Response Table for mean

\begin{tabular}{ccccc}
\hline Level & $\begin{array}{c}\text { (A)Sliding time } \\
\text { (Second) }\end{array}$ & (B)lubricants & $\begin{array}{c}\text { (C)Load } \\
(\mathrm{N})\end{array}$ & $\begin{array}{c}\text { (D)Lube used } \\
\text { hours(hours) }\end{array}$ \\
\hline 1 & .6683 & 1.1756 & .9157 & 1.0871 \\
2 & 1.3156 & 1.0614 & 1.2751 & 1.1928 \\
3 & 1.6838 & 1.4307 & 1.4769 & 1.3878 \\
Delta & 1.0154 & .2692 & .5612 & .3007 \\
Rank & 1 & 4 & 2 & 3 \\
\hline
\end{tabular}

For the factors sliding distance, normal load applied and used hours of lubricant shows mean response values are increasing from leval1 to level 3 the optimum parameter level on the basis of response value was selected at minimum of response value of each level and the predicted level was A1B2C1D1 where A B C and $\mathrm{D}$ are the factors From these above response values the minimum values are observed at level 1 means sliding time10second, lubricants type 1, load 400 for unused or new lubricant. Rank in the table shows the severity of the factors Factor A affects most severely than the other factors D i.e. used hours shows minimum response. The data is given in Table4 from this data the plots are developed with the help of a software package MINITAB 14. These results are analyzed using ANOVA for the purpose of identifying the significant factors, which affect the Wear volume and Average pressure. The above plots show the variation of individual response with the four parameters i.e. sliding speed, lubricants type, and load and used hours of lubricant separately. In the plots, the $x$-axis indicates the value of each process parameter at three level and $y$-axis the response value. Horizontal line indicates the mean value of the response. Figure 1 shows the main effect plot for wear volume. The results show that with the increase in sliding speed, lubricants type, load and used hours of lubricant there is an increment in wear value. The sliding speed lubricants type load applied and used hours of lubricant are directly proportional to the corresponding wear values.

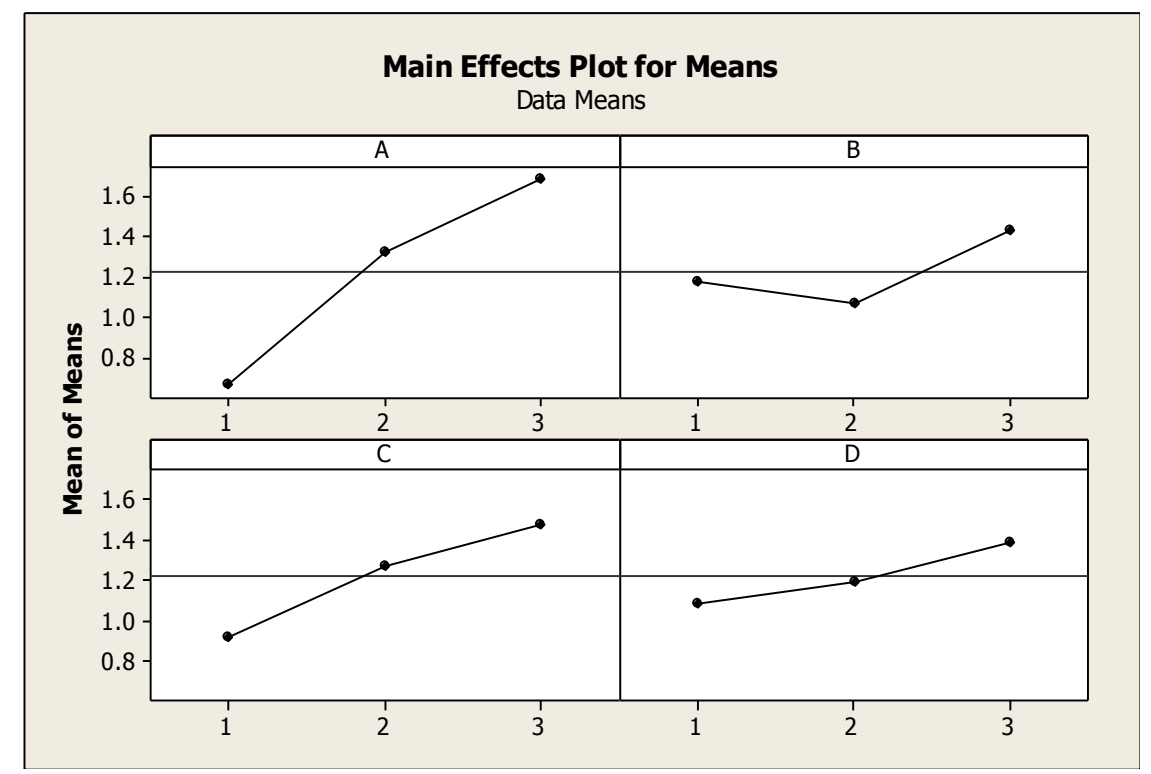

Fig. 2, Main Effect plots for Mean values for variables sliding time(A), lubricants(B), load(C),lubricant used hours(D)

From Figure 2 it can be seen that the maximum wear volume is obtained for the condition where sliding time is 30 seconds, lubricant type 3, load 500N and used hours4000 hours Minimum wear obtained for sliding time10second, lubricants type 1, load 400 and for new lubricant. From the figure it is observed that sliding speed affect more than remaining three factors. The $\mathrm{S} / \mathrm{N}$ ratio values are calculated by taking into consideration Equation 4. The wear values measured from the experiments and their corresponding S/N ratio 
values are listed in Table 4. The response table for the sliding time, lubricants type, loads and lubricant used hours and was created in the integrated manner and the results are given in Table 5. Regardless of the category of the performance characteristics, a greater $\mathrm{S} / \mathrm{N}$ value corresponds to a better performance. Therefore, the optimal level of the wear volume is the level with the greatest $\mathrm{S} / \mathrm{N}$ value.

Table .5Response Table for Signal to Noise Ratios (Smaller is better)

\begin{tabular}{ccccc}
\hline Level & (A)Sliding time & (B)lubricants & (C)Load(N) & $\begin{array}{c}\text { (D)Lube used } \\
\text { hours }\end{array}$ \\
\hline 1 & 5.8859 & 1.8559 & 3.3738 & 2.3905 \\
2 & -2.3497 & 0.1974 & -1.0339 & -0.4641 \\
3 & -4.4548 & -2.9719 & -3.2585 & -2.8451 \\
Delta & 10.3407 & 4.8278 & 6.6323 & 5.2356 \\
Rank & 1 & 4 & 2 & 3 \\
\hline
\end{tabular}

Figure 3 shows the effect of $\mathrm{S} / \mathrm{N}$ 's values where the $\mathrm{x}$-axis indicates the value of each process parameter at three level and $\mathrm{y}$-axis the response $\mathrm{S} / \mathrm{N}$ values. Horizontal line indicates the mean value of the response for average pressure. Figure shows the main effect plot of $\mathrm{S} / \mathrm{N}$ for average pressure. The results show that with the increase in sliding speed, lubricants type, load and used hours of lubricant there is and decrement in $\mathrm{S} / \mathrm{N}$ Values. It can be seen that the minimum $\mathrm{S} / \mathrm{N}$ response obtained at the $30 \mathrm{sec}$ sliding time, lubricant sample no1 3, load $500 \mathrm{~N}$ and 4000 used hours and maximum for 10second, lubricants type 1, load 400 for unused or new lubricant. As discussed above maximum values are to be considered in case of the smaller is better here minimum wear can predicted which are the maximum response values means at level one i.e. sliding time 10 second, load 400, lubricant sample no 1 , and for unused lubricants.

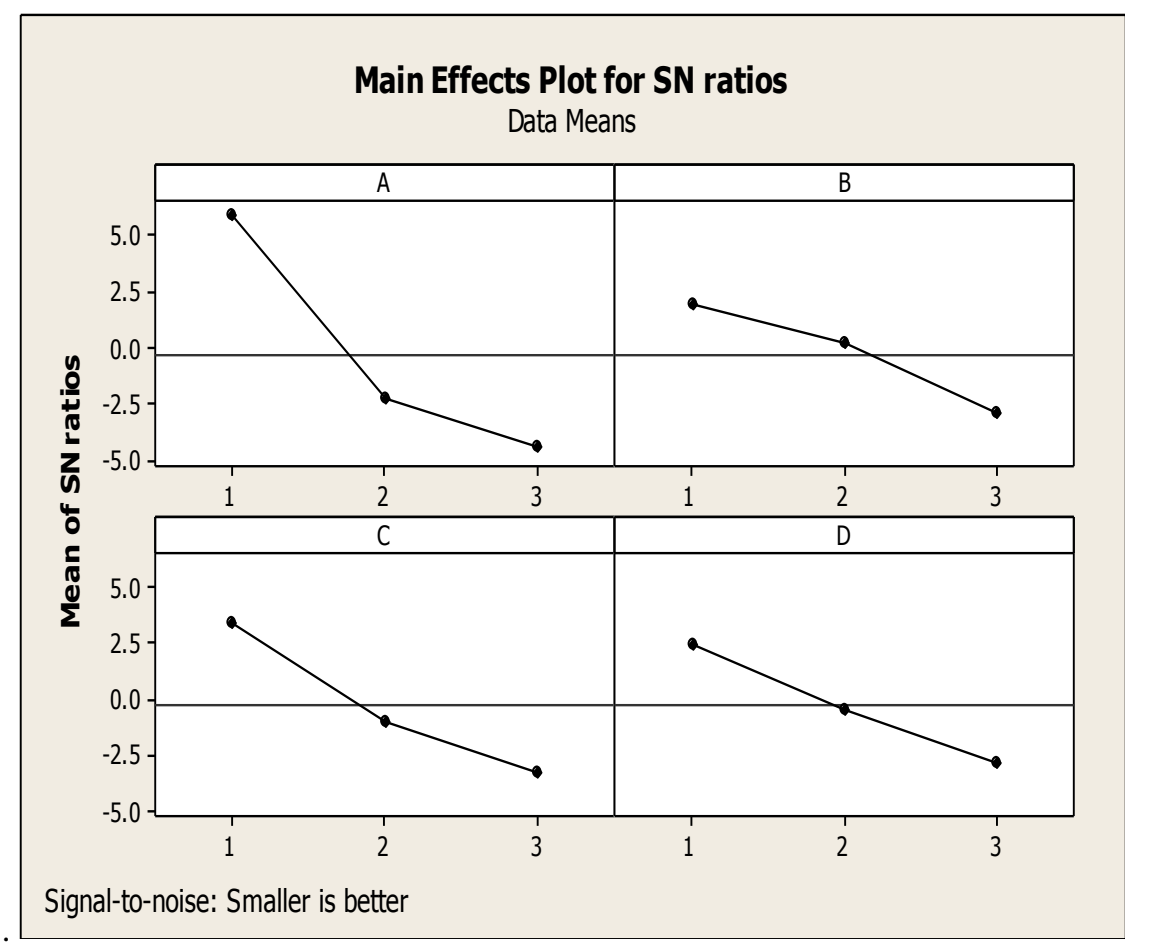

Fig.3.Figure showing effect of S/N's values for variables A B C and D for wear volume

It is interesting to observe that sliding time increases from 10 second to 20 second the $\mathrm{S} / \mathrm{N}$ values decreases means wear volume increases rapidly after 20 seconds to 30 seconds slope decreases it shows that sliding time affects more severely in the region 1 which is from level 1 to level 2. 


\section{ANALYSIS OF THE VARIANCE}

Even after decades of use, ANOVA forms the basis for discussion in the most prestigious statistical journals, leading off with the comment that "Analysis of variance (ANOVA) is an extremely important method in exploratory and confirmatory data analysis. The data analyzed using ANOVA methods are often collected from various experiments. There is always the possibility that some observations may contain excessive noise. Thus, even though the primary interest is in understanding how noise affects performance, this must be tempered by the fact that excessive noise during experiments might lead to incorrect inferences. The term "robustness" in the statistics literature is often used to refer to methods designed to be insensitive to distributional assumptions (such as normality) in general, and unusual observations ("outliers") in particular. The goal is not only to devise methodologies that yield results that are similar to those from standard methods when the underlying assumptions are satisfied, but also are relatively unaffected by rogue observations that are inconsistent with the general pattern in the data. Robust methods have been applied in virtually every area of scientific investigation, ANOVA method use standard (least squares) techniques, which are highly sensitive to unusual observations As such; it is possible that assessments of the importance of factors for quality design can be seriously compromised. In standard ANOVA, the underlying regression estimator is the least squares estimator, where parameters are chosen to minimize the regression sum of squares [9].

In order to perform ANOVA, the total sum of squared deviations, $S S_{\mathrm{T}}$ was calculated from the following formula $\mathrm{SS}_{\mathrm{T}}=\sum_{i=0}^{n} \mathrm{y}_{\mathrm{i}}^{2}$ - C.F ,(5). Where $\mathrm{n}$ is the number of experiments in the orthogonal array, $\mathrm{y}_{\mathrm{i}}$ : wear volume values, C.F.: correction factor, C.F was calculated as: C.F $=\mathrm{T}^{2} / \mathrm{n}$..(6), Where, T: is the total of the bending deflection under constant load. It should be noted that each test specimen was tested three times and thus the value of $\mathrm{n}$ was $27 \quad[14,15]$. The total sums of squared deviations, $\mathrm{SS}_{\mathrm{T}}$ was decomposed into two sources: the sum of squared deviations, $\mathrm{SS}_{\mathrm{d}}$ due to each process parameter and the sum of squared error, $\mathrm{SS}_{\mathrm{E}}$. The percentage contribution, $\mathrm{p}$ by each of the process parameter in the total sum of squared deviations, SST was a ratio of the sum of squared deviations, $\mathrm{SS}_{\mathrm{d}}$ due to each process parameter to the total sum of squared deviations, $\mathrm{SS}_{\mathrm{T}}[16]$. Statistically, there is a tool called $\mathrm{F}$ test to see which process parameters have significant effect on the quality characteristics. For performing the $\mathrm{F}$ test, the mean of squared deviations, $\mathrm{SS}_{\mathrm{m}}$ due to each process parameter needs to be calculated.

Table.6 ANOVA Table for wear test

\begin{tabular}{llccccc}
\hline Symbol & Parameters/ & $\begin{array}{l}\text { Degree } \\
\text { of freedom }\end{array}$ & $\begin{array}{c}\text { Sum of } \\
\text { squares }\end{array}$ & $\begin{array}{c}\text { Mean } \\
\text { square }\end{array}$ & F & Contribution (\%) \\
\hline A & Sliding time & 2 & 179.103 & 89.55 & 5.46 & 55.12412 \\
B & Lubricants type & 2 & 36.1392 & 18.06 & 1.10 & 11.12288 \\
C & Load & 2 & 68.4030 & 34.20 & 2.08 & 21.05295 \\
D & Lubricants used & 2 & 41.2636 & 20.63 & 1.25 & 12.70005 \\
& hours & 18 & 295.194 & 16.39 & & \\
Error & & 26 & 324.909 & & & 100 \\
Total & & & & &
\end{tabular}

The mean of squared deviations, $\mathrm{SS}_{\mathrm{m}}$ is equal to the sum of squared deviations; $\mathrm{SS}_{\mathrm{d}}$ divided by the number of degree of freedom associated with the process parameters. Then, the $\mathrm{F}$ value for each process parameter is simply the ratio of the mean of squared deviations, $\mathrm{SS}_{\mathrm{m}}$ to the mean of squared error, $\mathrm{SS}_{\mathrm{e}}$. Usually, when $\mathrm{F}>4$, it means that the change of the process parameter has significant effect on the quality characteristic Table 5 shows the results of ANOVA for the bending test. The F-ratios were obtained for $99 \%$ level of confidence. Table 6 shows the ANOVA table sliding time has the highest influence on the wear volume F-ratio of 5.46 and contribution of $55.12412 \%$ considerably higher when compared to those of lubricant type, load, and used hours shown in Tables suggest the aptness of the predicted model.

Table 7 Predicted and optimum wear values

\begin{tabular}{ccc}
\hline & \multicolumn{2}{c}{ Optimum wear parameters } \\
\hline & Prediction & Experiment \\
Level & A1B1C1D1 & A1B1C1D1 \\
Wear & 0.1649 & 0.179 \\
volume $\left(\mathrm{mm}^{3}\right)$ & & \\
\hline
\end{tabular}

and contribution $21.0529 \%$.Confirmation test was not required in the present case study because the optimum combination of parameters and their levels i.e. A1B1C1D1 correspond to experiment of the orthogonal array. It was observed that predicted values for wear volume are closer to the orthogonal array level. To conformed and 
improve the results the experiment was reconducted for the same level with the same samples and method explained in section 3 computed the wear volume and Average pressure .The average of readings was considered and compared the values with estimated values as shown in Table 7.

\section{CONCLUSION}

1) In this research, we intended to design a process for optimizing lubricated wear conditions in elliptical contact conditions using Taguchi design. Sliding wear volume under the effect of new and used lubricants under different conditions can be successfully analyzed using Taguchi design of experiment.

2) The analysis of variance for Sliding wear volume under lubricated conditions shows that, that sliding time (or distance travelled) by the specimen is the most significant factor, whereas load and lubricant type, and lubricant used hours has comparatively little contribution towards the wear characteristics.

3) In this study, the cross cylinder method used was found effective for lubricant testing as it required less time and same sample can be used for testing by changing its position of contact area to reduce the cost of testing.

\section{REFERENCES}

[1] Biswajit Bera, Adhessional Friction Law and Adhesive Wear Law of Micromechanical Surface Contact, IJERA, 2(5),2012,404-411

[2] Simon J. Montgomery1, David M. Kennedy1 \& Noel O’Dowd, Analysis of wear models for advanced coated materials, Conference on Materials, Tribology, Recycling, Lipanj, Croatia, June 2009,24-26

[3] Alfred Zmitrowicz, Wear patterns and laws of wear-A review, Journal of theoretical and applied,44(2), 2006, 219-253

[4] B. Zhu and G.L. Kelly frictional behaviour and wear performance of a nitrocarburised coating sliding against aisi 1019 steel materials forum ,IMEA,27, $2004,54-61$

[5] A.W.Ruff and Myshkin, Lubricated Wear Behavior of Composition-Modulated Nickel-Copper Coatings, Journal of Tribology 111 (1),2009,111-156

[6] Begelinger A, De Gee, A .W. J, Failure of thin film lubrication-The effect of running-in on the load carrying capacity of thin-film lubricated concentrated contacts International Lubrication Conference, San Francisco, Calif.ASME,6, 1980, 18-21

[7] S. M. Mahdavian, Y. W. Ma1 and B. Cotterell, Friction, metallic transfer and debris analysis of Sliding surfaces, Wear, $82,1982,221$ - 232

[8] S. M. Madhavian and Y. W. Mai, Further study in friction, metallic transfer and wear debris of sliding surfaces, Wear, 95, 1984,35-44

[9] Ho-Hsien Chen, Chao-Chin Chung, Han-Yan Wang and Tzou-Chi Huang, Application of Taguchi Method to Optimize Extracted Ginger Oil in different Drying Conditions ,Proc. International conference International Conference on Food Engineering and Biotechnology,Singapoore,IPCBEE,9,2011,310-316

[10] K. L. Johnson, Adhesion and friction between a smooth elastic spherical asperity and a plane surface, Cambridge University, 1 New Square, Cambridge ,1997,453,163-179

[11] J. Warburton and R. Bradford, The Progressive wear of tubes; the volume of the interaction of the cylinders with each other and with flats, Wear 113,1986,331-352

[12] F. P. Bowden and D. Tabor, The Area of Contact between Stationary and between Moving Surfaces, Laboratory of physical science, (Cambridge 1939)

[13] A Case Study of Taguchi Method in the Optimization of Turning Parameters International Journal of Emerging Technology and Advanced Engineering,3(2), 2013,616-626

[14] Priya S. Dhote, Vinod N. Ganvir, Yadavalli C. Bhattacharyulu, Optimization of mahua oil methyl ester by using taguchi experimental design,IJAET,6(3),2013,1140-1145

[15] S. Kamaruddin,Zahid A. Khan ,K. S. Wan, The use of the taguchi method in determinating the optimum plastic injection moulding parameters for the production of a consumer product ,Jurnal Mekanikal, $18,2004,98-110$ 